\title{
A Novel Eyelashes Removal Method for Improving Iris Data Preservation Rate
}

\author{
Seong-Hoon $\mathrm{Kim}^{\dagger} \cdot$ Gi-Tae $\mathrm{Han}^{+\dagger}$
}

\begin{abstract}
The iris recognition is a biometrics technology to extract and code an unique iris feature from human eye image. Also, it includes the technology to compare with other's various iris stored in the system. On the other hand, eyelashes in iris image are a external factor to affect to recognition rate of iris. If eyelashes are not removed exactly from iris area, there are two false recognitions that recognize eyelashes to iris features or iris features to eyelashes. Eventually, these false recognitions bring out a lot of loss in iris informations. In this paper, in order to solve that problems, we removed eyelashes by gabor filter that using for analysis of frequency feature and improve preservation rate of iris informations. By novel method to extract various features on iris area using angle, frequency, and gaussian parameter on gabor filter that is one of the filters for analysing frequency feature for an image, we could remove accurately eyelashes with various lengths and shapes. As the result, proposed method represents that improve about $4 \%$ than previous methods using GMM or histogram analysis in iris preservation rate.
\end{abstract}

Keywords: Eyelashes Detection, Eyelid Detection, Pupil Detection, Gabor Filter, Iris Recognition

\section{홍채영역에서의 홍채정보 보존율 향상을 위한 새로운 속눈썹 제거 방법}

\author{
김 성 훈 $^{+}$한 기 태 ${ }^{++}$
}

\begin{abstract}
요
약

홍채 인식은 인간의 눈 영상으로부터 고유한 홍채특징을 추출하고 이를 코드화 하여 비교하는 생체인식 기술로, 이것은 시스템 안에 저 장된 다른 홍채들과의 비교기술을 포함한다. 한편, 홍채 영상에서의 속눈썹은 인식률에 영향을 미치는 외부 요소인데, 만일 속눈썹이 홍채 영역으로부터 정확하게 제거되지 않는다면 속눈썹을 홍채특징으로 인식하거나 홍채특징을 속눈썹으로 인식하는 오인식의 문제가 존재하게 되며, 결국 이 오인식은 홍채정보의 많은 유실을 가져오게 된다. 따라서 본 논문에서는 이러한 문제점을 해결하기 위하여 주파수 특징 분석 에 사용되는 Gabor Filter를 이용한 속눈썹 제거로 홍채정보의 보존율 향상을 가져올 수 있었다. Gabor Filter는 영상의 주파수 분석을 위 한 필터 중 하나인데 여기에 각도, 주파수, 가우시안 파라미터 등을 이용한 다양한 홍채영역의 특징들을 추출할 수 있는 새로운 방법으로 다양한 길이와 모양의 속눈썹을 정확하게 제거할 수 있었다. 그 결과 제안한 방법은 GMM 혹은 히스토그램 분석을 이용한 기존 방법보다 홍채영역 데이터 보존율에 있어서 약 $4 \%$ 정도의 향상이 가능하였다.
\end{abstract}

키워드 : 속눈썹 검출, 눈꺼풀 검출, 동공 검출, 가버 필터, 홍채인식

\section{1. 서 론}

생체인식 기술과 하드웨어의 발전에 따라 현재 실생활에 생체인식 장치들이 빠르게 보급되고 있다. 생체인식 기술에

※ 본 논문은 중소기업청에서 지원하는 2013년도 산학연공동기술개발사업 는 대표적으로 지문인식, 홍채인식 등이 있으며, 그중에서도 (No.20130394)의 연구수행으로 인한 결과물임.

† 준 회 원 : 가천대학교 전자계산학과 석사과정

†† 정 회 원: 가천대학교 컴퓨터공학과 교수

Manuscript Received: May 21, 2014

First Revision: September 16, 2014

Accepted: September 16, 2014

* Corresponding Author:Gi-Tae Han(gthan@gachon.ac.kr) 홍채인식은 생체인식 기술 중에 가장 높은 인식률을 나타내 는 기술로 기업에서의 문서보안, 출입통제 시스템 등으로 활용되어 왔으며 최근에는 스마트폰 보안, 차량 보안 등에 서도 활용하기 위한 연구들이 진행되고 있다 $[1,2]$. 
홍채인식은 사람마다 고유한 홍채특징을 저장하고 이를 비교하여 인식하는 방법으로 적외선 카메라로 촬영된 눈 영 상에서 동공과 홍채의 둘레를 나타내는 홍채 테두리를 검출 하여 홍채영역을 추출하고 홍채영역에서 고유한 홍채특징을 추출한다. 또한 추출된 홍채특징은 차후에 입력되는 데이터 와 비교하기 쉽도록 홍채코드를 생성하여 저장한다. 따라서 최초에 저장될 홍채코드 생성 시 외부 요소에 의해 홍채특 징들이 가려진다면 홍채정보의 손실로 인하여 고유한 홍채 코드를 생성할 수 없으므로 인식률의 저하가 발생한다[3, 4].

홍채 인식에서 홍채정보 손실에 영향을 주는 외부 요소로 는 영상의 노이즈, 속눈썹, 장애물 등이 있으며, 이 중 속눈 썹은 홍채 인식률 저하에 가장 많은 영향을 미치는 외부 요 소로서 이를 검출하여 홍채영역에서 제거하여 홍채코드를 생성하거나 속눈썹이 포함된 홍채영역을 배제한 영역만을 사용하는 방법들이 연구되고 있다.

기존의 Zhaofeng $\mathrm{He}$ 가 제안한 속눈썹 검출 방법은 촬영 된 눈 영상에서 홍채영역을 검출하고 속눈썹이 포함된 홍채 영역(Eyelashes Area, EA)과 속눈썹이 포함되지 않은 홍채 영역(Iris Area, IA)을 임의로 설정한다. 설정된 두 영역의 히스토그램을 분석하면 속눈썹은 일반적으로 어두운 픽셀값 을 갖는 특징을 갖고 있어 속눈썹이 포함된 홍채영역 $\mathrm{EA}$ 는 낮은 값을 나타내는 히스토그램을 가지며, 속눈썹이 포함되 지 않은 홍채영역 IA는 상대적으로 $\mathrm{EA}$ 보다 높은 값의 히스 토그램을 갖는다. 따라서 IA와 $\mathrm{EA}$ 를 분리할 수 있는 임계 값을 설정하고, 임계값 이하의 픽셀들은 속눈썹으로 검출한 다. 이는 사람에 따라 다른 눈썹의 길이에 따라 속눈썹 포 함 영역인 $\mathrm{EA}$ 가 유동적으로 커지거나 줄어들지 않으므로 속눈썹의 일부분이 검출되지 않으며 잘못 설정된 임계값은 홍채특징마저 속눈썹으로 검출되어 홍채데이터를 유실하는 단점이 있다[5].

Ting Wang이 제안한 속눈썹 검출 방법은 Gaussian Mixture Model(GMM)과 Expectation Maximization(EM)을 이용하여 전체 눈 영상의 히스토그램을 다양한 형태를 갖는 여러 개 의 가우시안의 합으로 표현하고 속눈썹에 해당되는 가우시 안을 검출하는 방법으로, 검출 속도는 빠를 수 있으나 촬영 된 눈 영상의 조명 상태에 따라 히스토그램의 모양이 변할 수 있으므로 속눈썹의 일부분이 제대로 검출되지 않아 홍채 코드 생성에 문제를 발생시키는 단점이 있다[6].

본 논문에서는 이러한 단점을 보완하기 위하여 홍채영역 에서 영상 주파수 분석에 활용되는 Gabor Filter를 사용하여 속눈썹을 검출한다. 특히 속눈썹은 사람마다 다양한 각도와 길이를 가진다는 특징을 갖고 있으므로 이러한 특징에 맞게 속눈썹을 검출하기 위하여 여러 개의 각도 값을 갖는 Gabor Filter를 생성하여 다양한 형태의 속눈썹을 정확히 검출하여 제거함으로써 홍채정보 보존율을 향상시키는 방법을 제안한다.

\section{2. 관련 연구}

\section{$2.12-D$ Gabor Filter}

2-D Gabor Filter는 영상의 주파수 분석에 사용되는 필터 로 경계선 검출, 특징 검출에 사용되며 아래 Equation (1)과 같이 2-D Gabor Filter $g(x, y)$ 는 사인평면파 $s(x, y)$ 와 Gaussian Envelope $w_{r}(x, y)$ 의 곱으로 이루어져 있다[7, 8].

$$
g(x, y)=s(x, y) \times w_{r}(x, y)
$$

사인평면파 $s(x, y)$ 는 아래 Equation (2)로 정의되며 복 소의 형태를 가지고 있어 실수부(Real part)와 허수부 (Imaginary part)로 나누어진다. 또한 여러 형태의 주파수 분석을 위해 주파수 파라미터 $u_{0}$ 와 $v_{0}$, 주파수 위상 파라미 터 $\mathrm{P}$ 를 갖고 있으며 $u_{0}=v_{0}=1 / 80$ 이고, $\mathrm{P}=0$ 일 때 아래 Fig. 1 과 같이 나타난다.

$$
\begin{aligned}
& s(x, y)=\exp \left(j\left(2 \pi\left(u_{0} x+u_{0} y\right)+P\right)\right) \\
& \left.\operatorname{Re}(s(x, y))=\cos \left(2 \pi\left(u_{0} x+v_{0} y\right)+P\right)\right) \\
& \left.\operatorname{Im}(s(x, y))=\sin \left(2 \pi\left(u_{0} x+v_{0} y\right)+P\right)\right)
\end{aligned}
$$

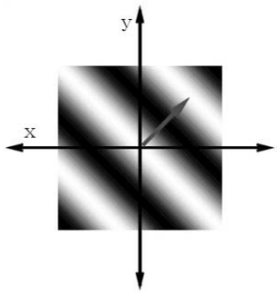

Fig. 1A. Real part

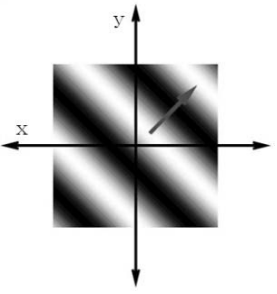

Fig. 1B. Imaginary part
Fig. 1. The real and imaginary parts of a complex sinusoid

Gaussian Envelope $w_{r}(x, y)$ 은 아래 Equation (3)으로 정의되며 2-D Gabor Filter의 형태를 조절할 수 있도록 Gaussian 스케일 파라미터 $\mathrm{K}$, Gaussian의 peak 파라미터 $x_{0}$ 와 $y_{0}$ 축에 대한 스케일 파라미터 $\mathrm{a}$ 와 $\mathrm{b}$, 각도 파라미터 $\theta$ 를 갖는다. $\mathrm{K}=1, x_{0}=y_{0}=0, \mathrm{a}=1 / 50, \mathrm{~b}=1 / 40, \theta=-45$ 도일 때 Gaussian Envelope는 아래 Fig. 2와 같이 나타난다.

$$
\begin{aligned}
& w_{r}(x, y)=K \exp \left(-\pi\left(a^{2}\left(x-x_{0}\right)_{r}^{2}+b^{2}\left(y-y_{0}\right)_{r}^{2}\right)\right) \\
& \left(x-x_{0}\right)_{r}=\left(x-x_{0}\right) \cos \theta+\left(y-y_{0}\right) \sin \theta \\
& \left(y-y_{0}\right)_{r}=-\left(x-x_{0}\right) \sin \theta+\left(y-y_{0}\right) \cos \theta
\end{aligned}
$$




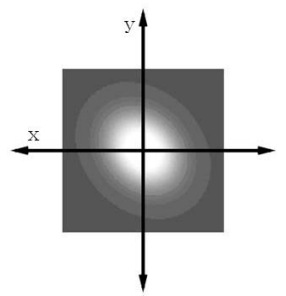

Fig. 2. Gaussian envelope

위의 식들을 정리하면 아래 Equation (4)와 같이 Gabor Filter를 정의할 수 있으며 총 9개의 파라미터를 갖는다. Gabor Filter의 파라미터가 $\mathrm{K}=1, \mathrm{a}=1 / 50, \mathrm{~b}=1 / 40, \quad \theta=-45$, $\mathrm{P}=0, u_{0}=v_{0}=\sqrt{2} / 80$ 일 때 아래 Fig. 3 과 같이 나타난다.

$$
\begin{aligned}
g(x, y)= & K \exp \left(-\pi\left(a^{2}\left(x-x_{0}\right)_{r}^{2}+b^{2}\left(y-y_{0}\right)_{r}^{2}\right)\right) \\
& \times \exp \left(j\left(2 \pi\left(u_{0} x+u_{0} y\right)+P\right)\right)
\end{aligned}
$$

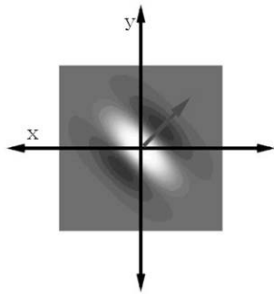

Fig. 3A. Real part

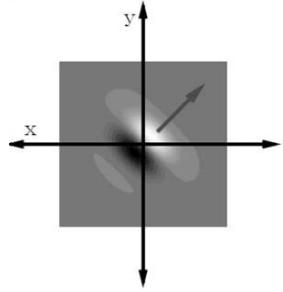

Fig. 3B. Imaginary part
Fig. 3. Gabor filter

Equation (4)로 정의된 Gabor 필터는 영상처리에 사용하 기 위해 아래 Equation (5)의 식으로 간소화할 수 있으며, 총 7 개의 파라미터로 Gabor 필터를 정의할 수 있다.

$$
\begin{aligned}
g(x, y, \lambda, \theta, \psi, \sigma, \gamma)= & \exp \left(-\frac{x^{\prime 2}+\gamma^{2} y^{\prime 2}}{2 \sigma^{2}}\right) \\
& \times \exp \left(i\left(2 \pi \frac{x^{\prime}}{\lambda}+\psi\right)\right)
\end{aligned}
$$

\section{2 허프 원 변환(hough circle transform)}

허프 원 변환은 눈 영상에서 동공 및 홍채 테두리 등 원 의 형태를 검출하기 위해 중심점과 반지름을 찾는 방법으로 Fig. 4와 같이 반지름 $\mathrm{r}$ 을 갖는 원 $\mathrm{C}$ 에 대해서 원의 둘레에 위치하는 $\mathrm{n}$ 개의 점 $P_{n}$ 을 중심으로 같은 $\mathrm{r}$ 의 값을 갖는 $\mathrm{n}$ 개 의 원을 그렸을 때 $\mathrm{n}$ 개의 원들이 서로 교차하는 지점 $P_{c}$ (point of cross)를 알 수 있으며, 원 $\mathrm{C}$ 의 중심이 가장 많은 교차점을 갖게 된다[9].
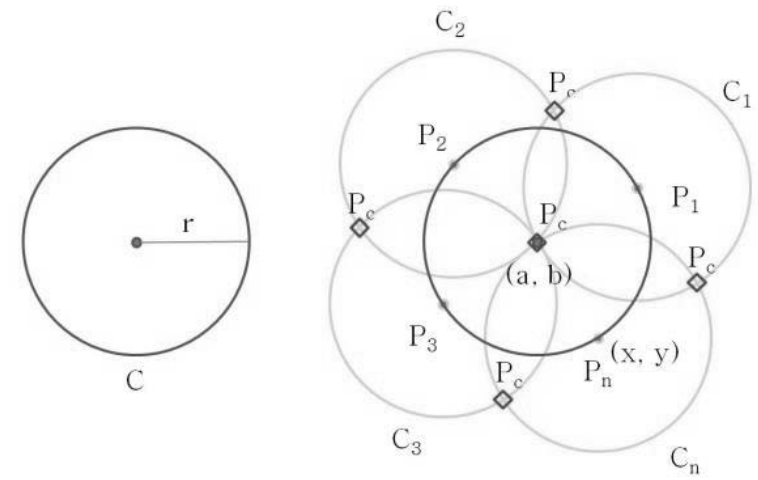

Fig. 4. Hough circle transform example

즉, 반지름 $\mathrm{r}$ 의 값을 갖는 원 $C_{n}$ 의 중심점 $(\mathrm{x}, \mathrm{y})$ 는 점 $(\mathrm{a}$, b)에서 반지름 $r$ 의 크기를 갖는 원의 둘레에 존재한다. 이를 식으로 표현하면 아래 Equation (6)과 같다.

$$
x=a+r \times \cos \theta, y=b+r \times \sin \theta
$$

이때, 점 $(x, y)$ 가 위치할 수 있는 원의 중심 $(\mathrm{a}, \mathrm{b})$ 는 반지 름 $\mathrm{r}$ 과 $0 \sim 360^{\circ}$ 까지의 $\Theta$ 값에 대하여 다음과 같이 Equation (7)로 표현할 수 있다.

$$
a=x-r \times \cos \theta, b=y-r \times \sin \theta
$$

위 Equation (2)를 이용하여 원의 중심점을 찾기 위해 먼 저 입력 영상의 외곽선(edge) 정보를 추출한다. 따라서 추출 된 외곽선의 모든 점 $(\mathrm{x}, \mathrm{y})$ 에 대해 반지름 $\mathrm{r}$ 의 크기일 때, 0 $\sim 360^{\circ}$ 까지의 $\Theta$ 값을 갖는 지점 (a, b)에 대해 hough space 에 투표(vote)를 실시하여 높은 투표값이 나타나는 위치가 원의 중심점임을 알 수 있다.

\section{3. 제안하는 방법}

본 논문에서 제안하는 방법은 Fig. 5와 같이 적외선 카메 라로 촬영된 눈 영상에서 동공 검출, 홍채 테두리 검출, 눈 꺼풀 곡선 검출, 속눈썹 검출과 같은 순서로 처리한다.

먼저 동공과 홍채 테두리 검출을 위해 사전처리 및 Hough Circle Transform을 통하여 동공 및 홍채 테두리 후보 위치 를 검출하고 동공의 픽셀들은 항상 낮은 픽셀 값을 갖는다 는 특징을 이용하여 동공 후보 위치 중에서 동공을 검출한 다. 또한 홍채 테두리 위치는 동공의 중심점과 거의 일치한 다는 특징을 갖고 있으므로 검출된 동공의 중심점과 홍채 테두리 후보들의 중심점 간의 거리계산을 통해 홍채 테두리 를 검출한다. 


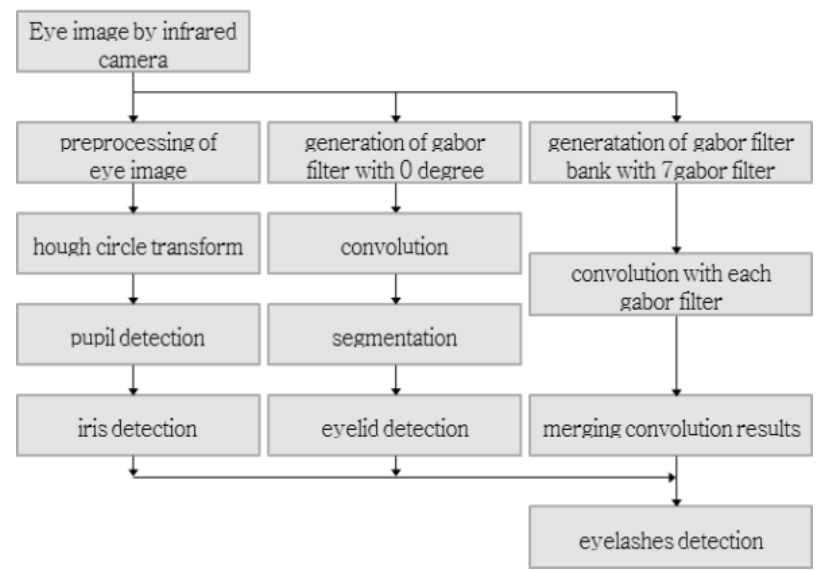

Fig. 5. Flowchart of algorithm

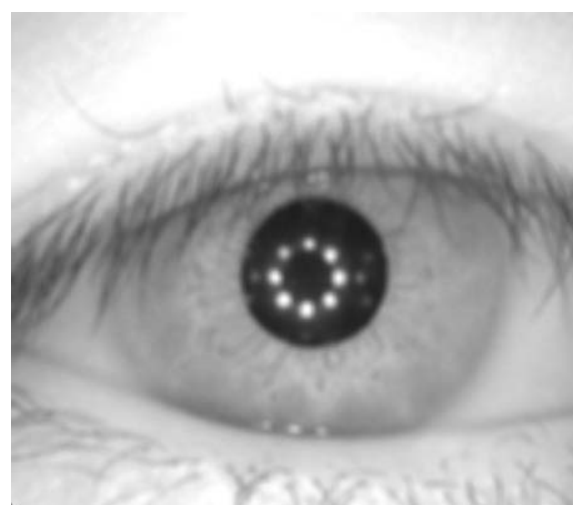

Fig. 6. Blurred eye image

눈꺼풀 곡선은 일반적으로 수평성분을 많이 갖는다는 특징을 가지고 있으므로 0도 값을 갖는 Gabor Filter를 이 용하여 수평 성분들을 검출하고 이를 영역분할하여 가장 큰 두 개의 수평 성분을 상단 및 하단 눈꺼풀 곡선으로 검출한다.

마지막으로 속눈썹 검출은 다양한 형태의 속눈썹을 검출 할 수 있도록 7개의 다른 각도 값을 갖는 Gabor Filter를 생 성하여 각각의 컨벌루션 결과를 병합하여 속눈썹 후보 영역 들을 검출하고, 속눈썹은 상단 눈꺼풀 곡선과 교차하거나 인접한다는 특징을 이용하여 속눈썹을 검출한다.

\section{1 동공 및 홍채 테두리 검출 방법}

동공 및 홍채 테두리 검출은 Hough Circle Transform을 통해 검출되며 먼저 동공의 위치를 검출한 후 홍채 테두리 의 위치를 검출한다.

눈 영상에서의 동공의 외곽선을 부드럽게 하여 Hough Circle Transform 연산 시 동공 후보 위치를 검출하는 성능 이 향상되도록 하기 위해 Gaussian fllter를 사용하여 눈 영 상을 Fig. 6과 같이 블러링 시킨다.

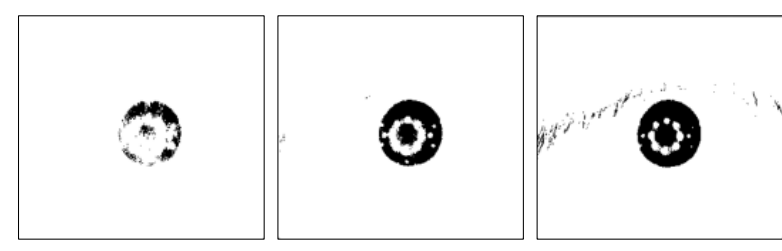

Fig. 7 A. $T=40 \quad$ Fig. 7 B. $T=60 \quad$ Fig. $7 C . ~ T=80$

Fig. 7. Experiment for obtain optimal threshold

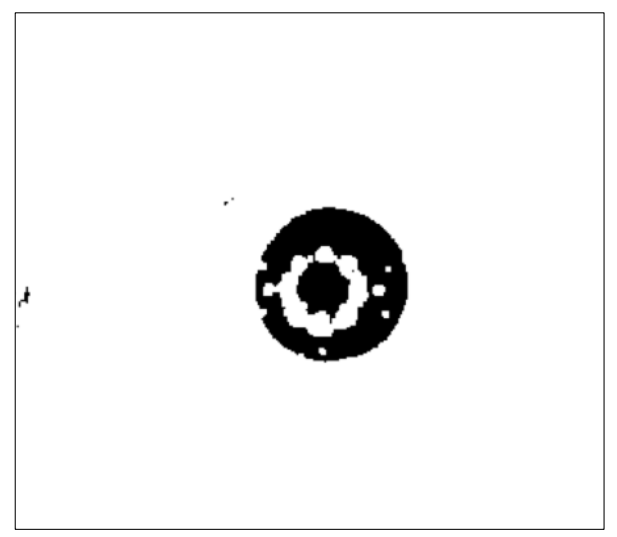

Fig. 8. Binarization of eye image

블러링 된 눈 영상에서 Fig. 7과 같이 실험을 통해 동공 을 제외한 불필요한 부분이 모두 제거되는 최적의 임계값 T를 얻어 Hough Circle Transform 연산 시 연산량이 최소 화되도록 아래 Fig. 8과 같이 이진화를 수행하고 Fig. 9와 같이 Hough Circle Transform을 수행하여 동공의 후보 위 치를 검출한다.

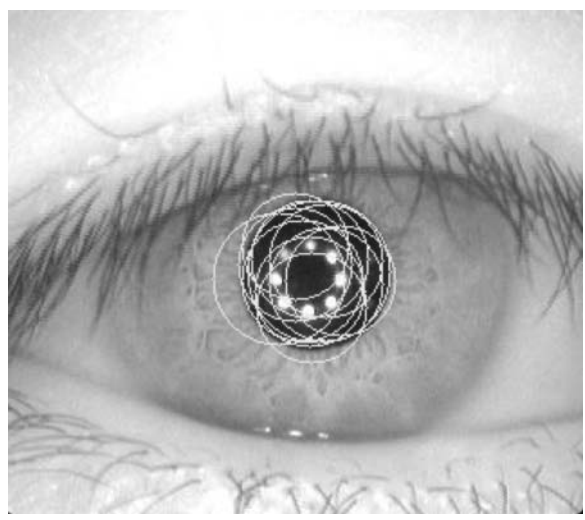

Fig. 9. Detect pupil candidates

검출된 후보 위치 중 동공의 위치를 결정하기 위해 이진 화 영상에서 후보 원 내의 0값을 갖는 픽셀의 개수를 누적 하여 가장 많은 값을 나타내는 후보를 Fig. 10과 같이 동공 의 위치로 결정한다. 


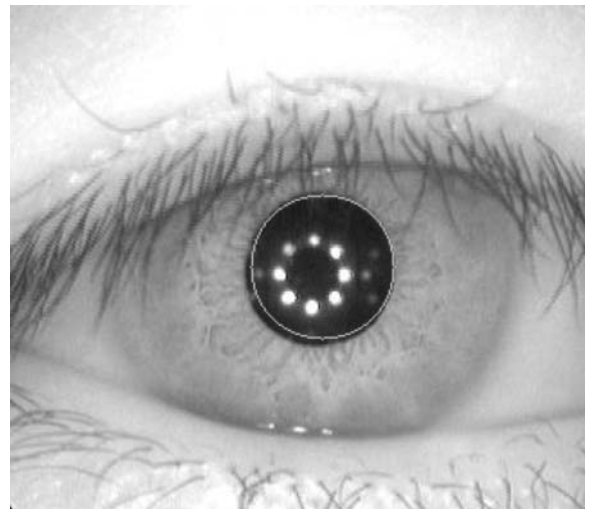

Fig. 10. Decision of pupil position in candidates

다음으로 홍채 테두리의 후보 위치를 검출하기 위해 Fig. 11 과 같이 원 영상에서 히스토그램 평활화를 수행하고, 동 공 검출 시 사용된 Gaussian filter를 사용하여 Fig. 12와 같 이 블러링을 시킨다.

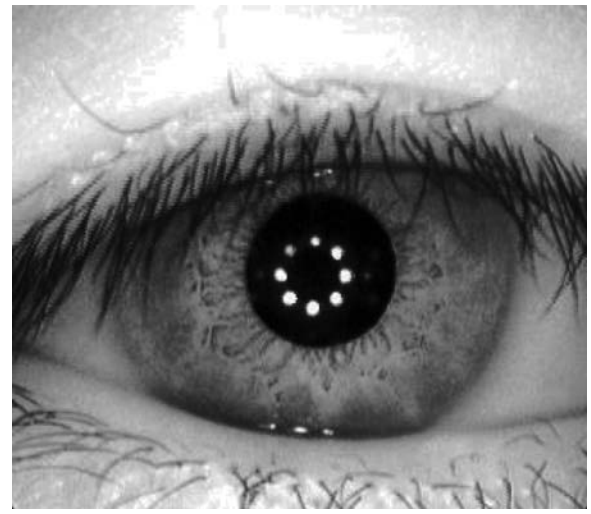

Fig. 11. Histogram equalization of eye image

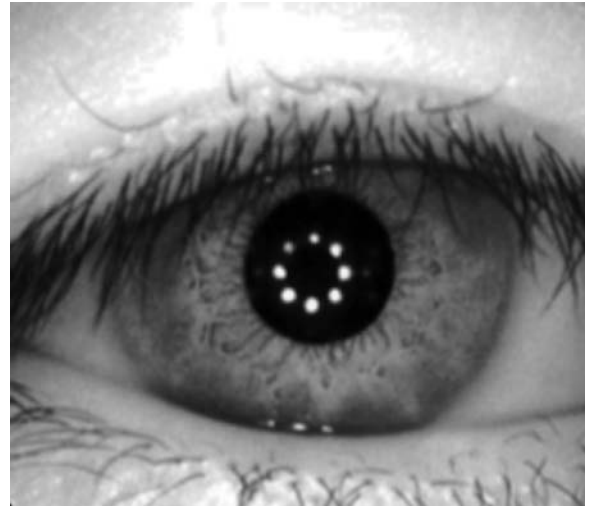

Fig. 12. Blurred eye image

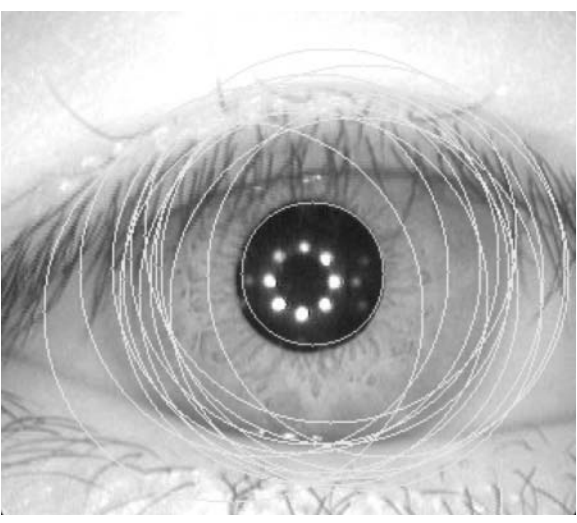

Fig. 13. Detect iris outline candidates

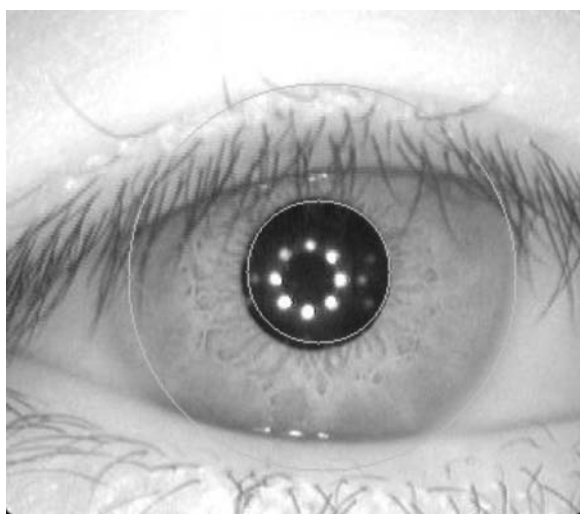

Fig. 14. Decision of iris outline in candidates

블러링 된 영상에서 Hough Circle Transform을 통하여 Fig. 13 과 같이 홍채 테두리 후보 위치를 검출하고, 후보 중 에서 홍채 테두리 위치를 결정하기 위해 동공의 중심점과 홍채 테두리 후보들의 중심점 간의 거리를 계산하여 가장 작은 값을 갖는 후보를 Fig. 14와 같이 홍채 테두리의 위치 로 결정한다.

\section{2 눈꺼풀 곡선 검출 방법}

눈꺼풀 곡선은 일반적으로 수평 성분을 갖는다는 특징을 갖고 있으므로 아래 Fig. 15와 같이 수평성분 검출에 최적 화되도록 0 도의 각도 파라미터와 실험을 통하여 얻은 주파 수 파라미터를 이용하여 Gabor Filter를 생성하고, 눈 영상 과 컨벌루션 수행을 통해 Fig. 16 과 같이 수평성분을 검출 할 수 있도록 한다. 


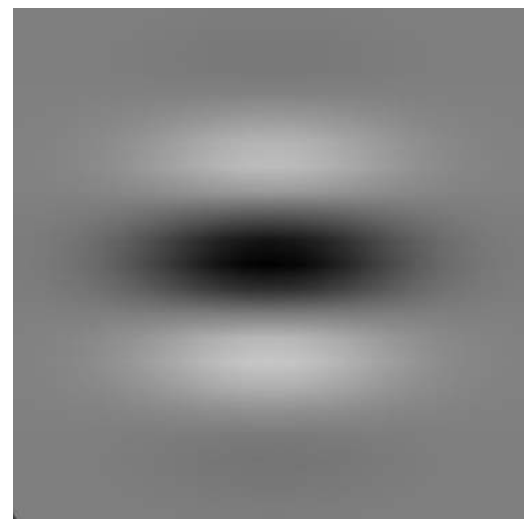

Fig. 15. Gabor filter with zero degree parameter

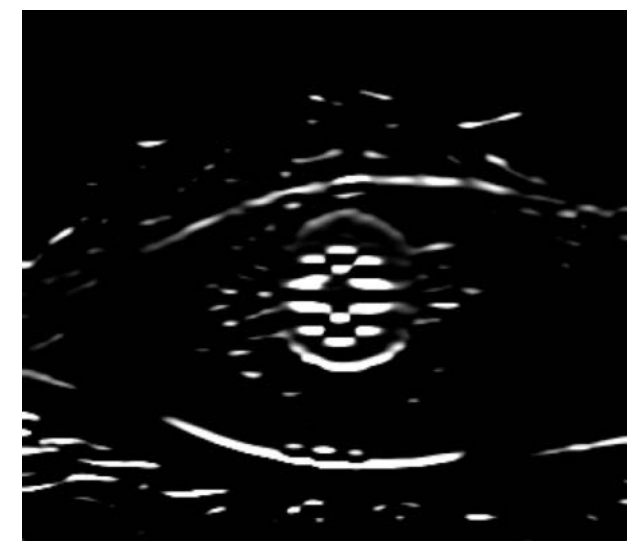

Fig. 16. Convolution result by gabor filter

검출된 눈꺼풀 수평 성분은 속눈썹이나 촬영된 영상에 따 라 끊어짐이 발생하여 약한 연결을 갖는다. 따라서 이를 보 완하기 위하여 Fig. 17과 같이 이진화를 수행하고 모폴로지 연산을 통해 약한 연결을 가지는 수평 성분들을 강한 연결 이 되도록 한다.

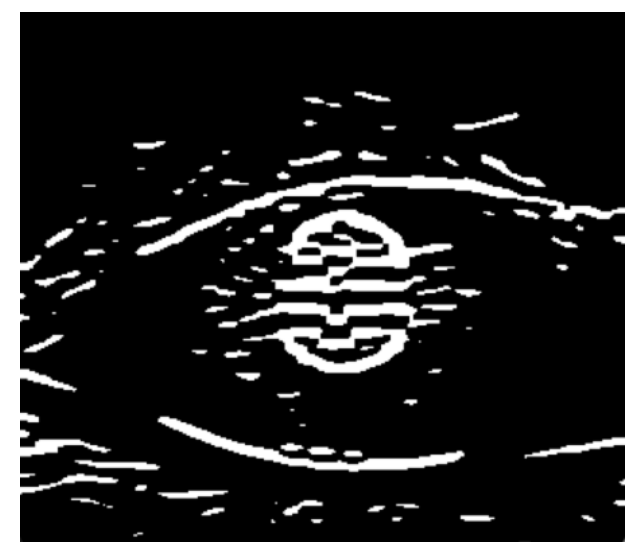

Fig. 17. The result of binarization and morphology for strong connection of horizontal components
수평 성분이 강한 연결들로 이루어진 이진화 영상에서 255의 값을 갖는 픽셀에 labeling을 통해 영상 분할을 수행 하는 Blob Labeling 알고리즘을 이용한 영상 분할을 수행한 다[9]. 영상 분할 결과 작은 크기의 영역들과 홍채영역을 벗 어나는 영역들은 모두 제거하여 아래 Fig. 18 과 같이 눈꺼 풀 후보를 검출한다.

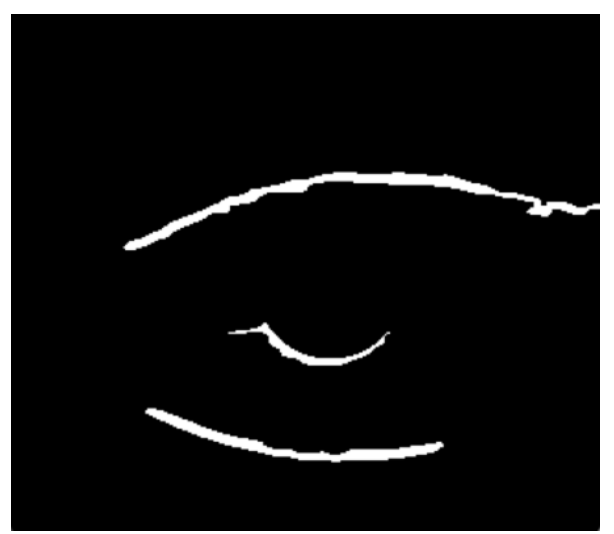

Fig. 18. Detect eyelid candidates

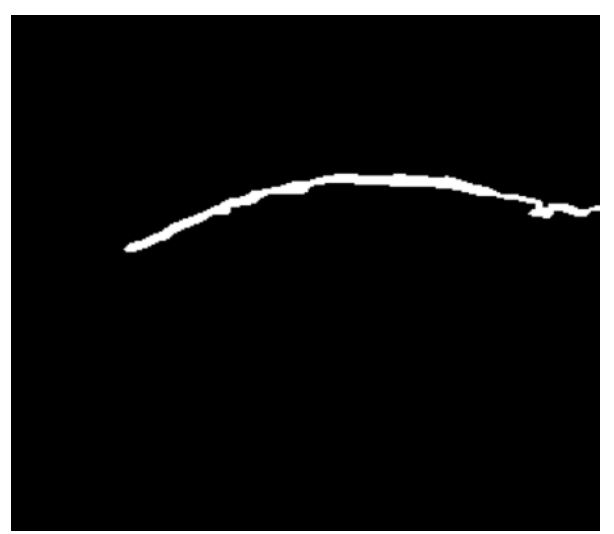

Fig. 19. Detect top eyelid

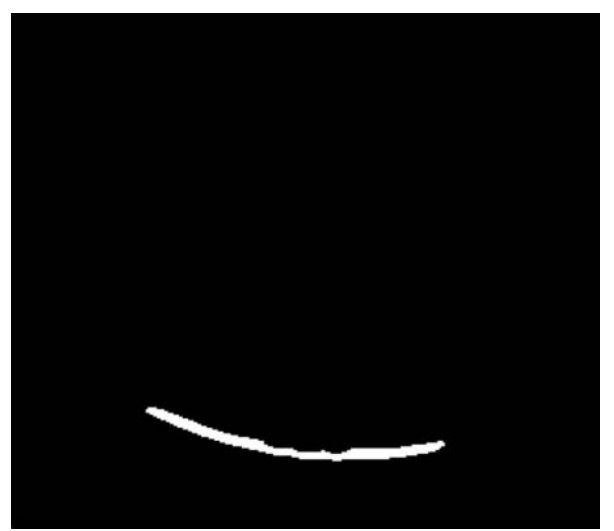

Fig. 20. Detect bottom eyelid 
눈꺼풀 후보에서 상단 눈꺼풀 검출은 동공의 중심점을 기 준으로 상단에 위치하여 있으며, 사람에 따라 외꺼풀 또는 쌍꺼풀 형태를 나타내므로 눈꺼풀 후보 중 가장 큰 영역을 나타내는 2 개의 영역을 선택하여 2개의 후보 중 가장 아래 쪽에 위치한 눈꺼풀 후보를 Fig. 19와 같이 상단 눈꺼풀로 지정한다. 또한 동공의 중심점을 기준으로 하단에 위치한 눈꺼풀 후보들 중 가장 큰 영역을 나타내는 눈꺼풀 후보를 Fig. 20과 같이 하단 눈꺼풀로 지정한다.

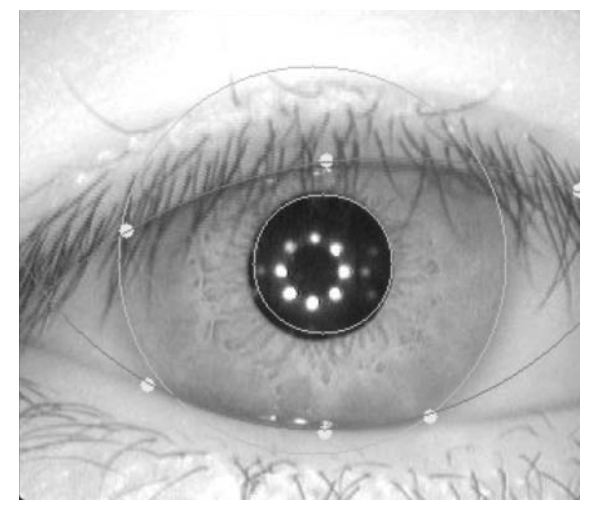

Fig. 21. Detection of eyelid curve

검출된 상-하단 눈꺼풀 영역을 이용하여 눈꺼풀 곡선을 그리기 위해 상단 눈꺼풀 영역의 최우측점, 최좌측점, 최상 단점과 하단 눈꺼풀의 최우측점, 최좌측점, 최하단점을 아래 Equation (8)과 같이 원의 방정식을 이용하여 Fig. 21과 같 이 눈꺼풀 곡선을 생성한다.

$$
x^{2}+y^{2}+A x+B y+C=0
$$

\section{3 속눈썹 검출 방법}

속눈썹 검출은 아래 Equation (9)와 같이 실수부에 해당 되는 Gabor 필터 정의를 사용하여 생성된 필터 기반으로 검출한다. Gabor 필터는 영상에서의 주파수 분석에 최적화 된 필터로 주파수 파라미터, 가우시안 파라미터, 각도 파라 미터 등을 입력하여 생성하며 아래 Fig. 22와 같이 실험을 통해 눈꺼풀 검출을 위한 최적의 주파수 파라미터 $\lambda$ 를 설 정한다.

$$
\begin{aligned}
g(x, y, \lambda, \theta, \psi, \sigma, \gamma)= & \exp \left(-\frac{x^{\prime 2}+\gamma^{2} y^{\prime 2}}{2 \sigma^{2}}\right) \\
& \times \cos \left(2 \pi \frac{x^{\prime}}{\lambda}+\psi\right)
\end{aligned}
$$
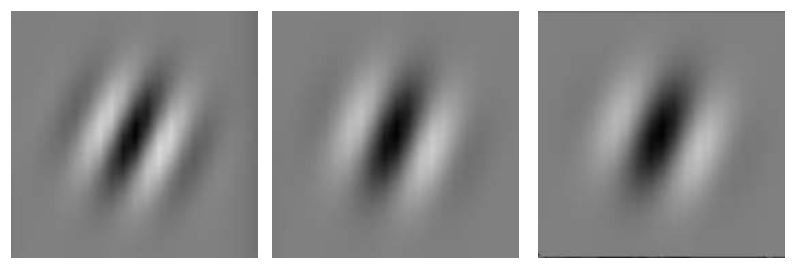

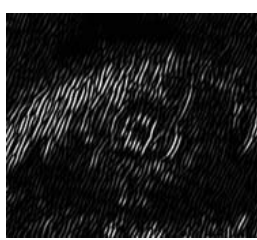

Fig. 22A. $\lambda=0.125$

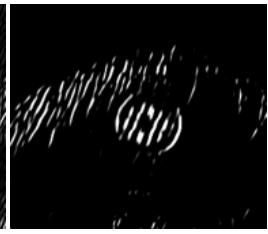

Fig. 22B. $\lambda=0.255$

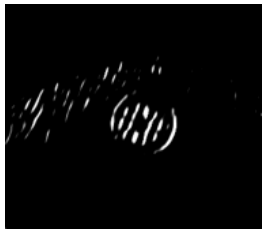

Fig. 22C. $\lambda=0.505$
Fig. 22. Decision of gabor filter's frequency parameter

주파수 파라미터 $\lambda$ 값에 의해 생성된 Gabor 필터의 사인 평면파의 주기가 속눈썹의 두께와 거의 일치할 때 가장 좋 은 결과를 나타내며 $\lambda$ 값이 0.255 일 때 가장 좋은 검출 결과 를 얻을 수 있었다.

또한 각도 파라미터는 사람마다 다양한 각도의 속눈썹을 검출할 수 있도록 하며 최소한의 각도 파라미터들을 이용하 여 속눈썹을 검출 시 계산량을 최소화하기 위해 아래 Fig. 23 과 같이 실험을 통하여 최소한의 Gabor Filter 개수로 최 적의 속눈썹 후보 영상을 얻도록 하였다. 실험은 0도에서 180 도 범위 내에서 180 개에서 3 개까지의 일정한 간격의 각 도를 갖는 Gabor Filter를 생성하여 원본 눈 영상에 컨벌루 션한 결과를 하나의 영상으로 병합한 결과를 비교하였으며, 그 결과 Fig. $23 \mathrm{C}$ 와 같이 7 개의 Gabor Filter를 이용했을 때 가장 좋은 결과를 나타냈다.

두 실험을 통해 생성된 최적의 주파수와 각도 파라미터를 갖는 Gabor Filter들은 아래 Fig. 24와 같으며 각각의 필터 를 원본 눈 영상에 컨벌루션 한 결과는 Fig. 25와 같다. 컨 벌루션하여 얻은 각각의 결과는 아래 Equation (10)에 의해 그림 Fig. $23 \mathrm{C}$ 와 같이 병합된다.

$$
I\{M I(x, y)\}=\sum_{n=1}^{k} I\left\{C I_{n}(x, y)\right\} \quad k=7
$$




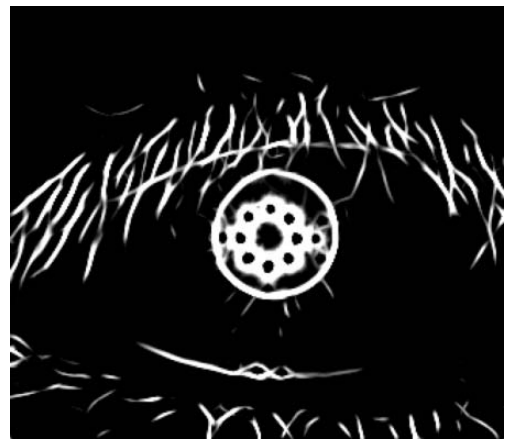

Fig. 23A. Convolution result with one hundred gabor filters

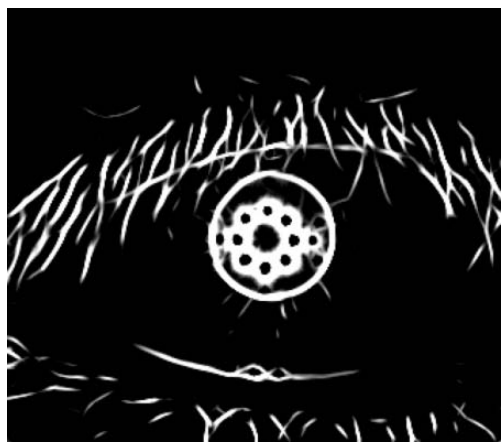

Fig. 23B. Convolution result with twenty gabor filters

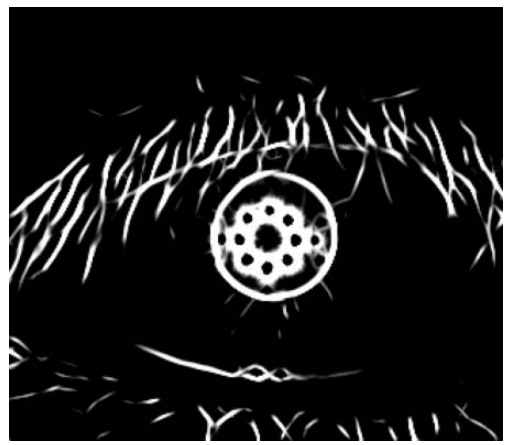

Fig. 23C. Convolution result with seven gabor filters

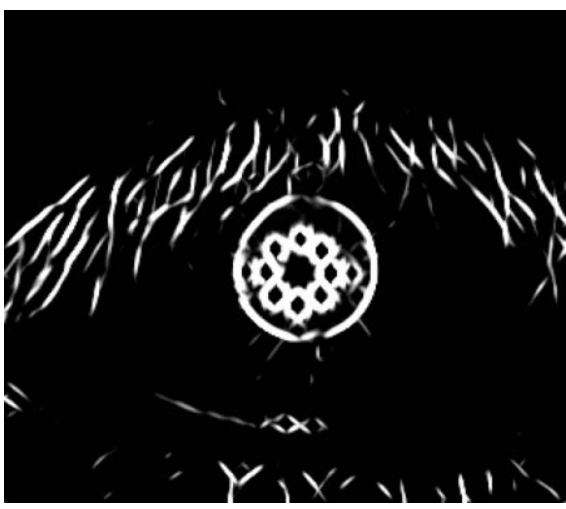

Fig. 23D. Convolution result with five gabor filters

Fig. 23. Convolution results according to degree parameter of gabor filter

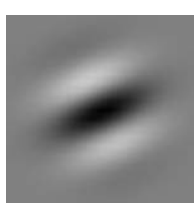

Fig. 24A. $\theta=22.5 \lambda=0.255$

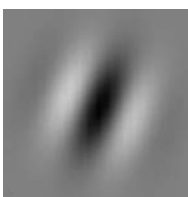

Fig. 24C. $\theta=67.5 \lambda=0.255$

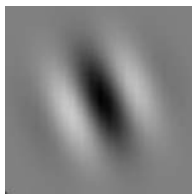

Fig. 24E. $\theta=112.5 \lambda=0.255$

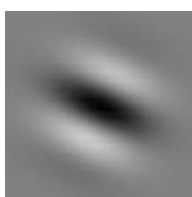

Fig. 24G. $\theta=157.5 \lambda=0.255$

Fig. 24. Gabor filter generation with optimal degree parameter and frequency parameter

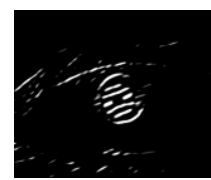

Fig. 25A. $\theta=22.5 \lambda=0.255$

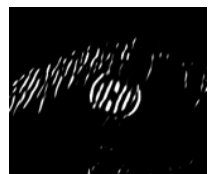

Fig. 25C. $\theta=67.5 \lambda=0.255$

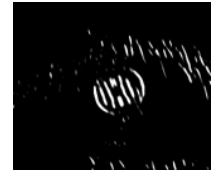

Fig. 25E. $\theta=112.5 \lambda=0.255$

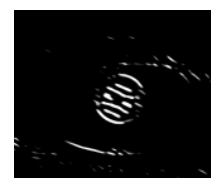

Fig. 25G. $\theta=157.5 \lambda=0.255$

Fig. 25. Convolution result with each gabor filter

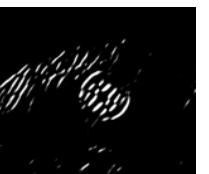

Fig. 25B. $\theta=45 \lambda=0.255$

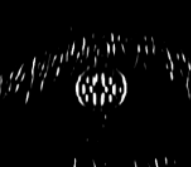

Fig. 25D. $\theta=90 \lambda=0.255$

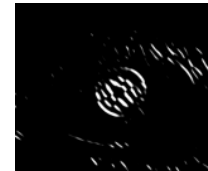

Fig. 25F. $\theta=135 \lambda=0.255$ 
병합된 컨벌루션 영상은 속눈썹 후보로 사용되며 속눈썹 은 눈꺼풀 곡선과 교차하거나 인접한다는 특징을 이용하여 속눈썹을 검출한다. 먼저 불필요한 후보를 제거하기 위해 Fig. $23 \mathrm{C}$ 의 병합된 결과 영상에서 홍채영역 밖에 위치한 영역과 동공영역 내에 위치한 영역을 제거한 영상은 Fig. 26 과 같다.
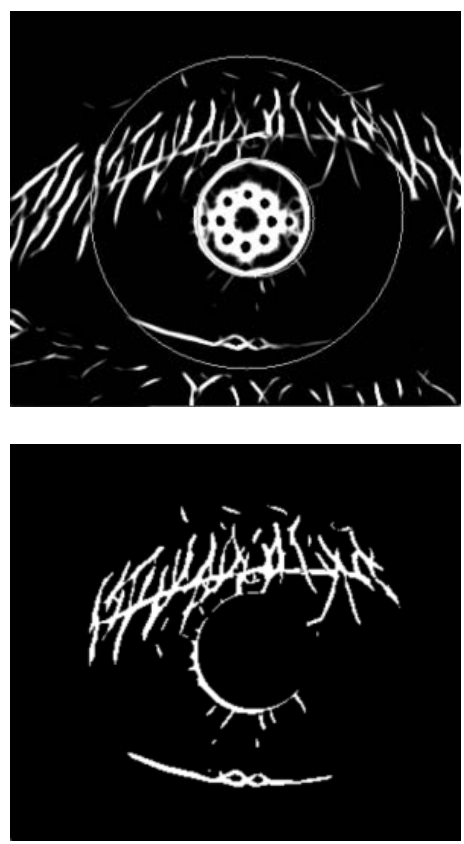

Fig. 26. Extraction eyelash candidates in iris region

홍채영역에 포함되는 속눈썹 후보에서의 속눈썹 검출은 이전에 검출된 눈꺼풀 곡선을 이용하며, 눈꺼풀 곡선과 겹 치거나 인접하는 속눈썹 후보 영역을 Fig. 27과 같이 속눈 썹으로 결정한다.

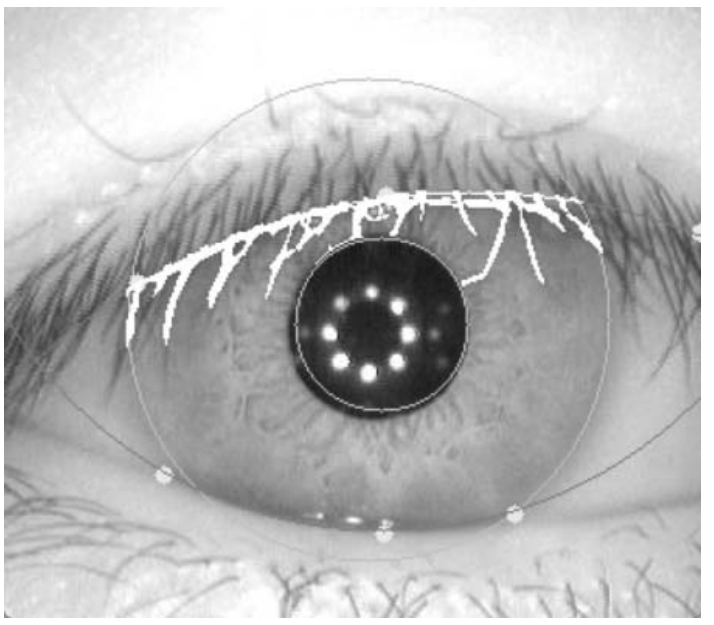

Fig. 27. Decision eyelashes with eyelid curve

\section{4. 실험 결과}

본 논문의 실험을 위한 환경 및 구현은 $\mathrm{CPU}$ i5 $2.2 \mathrm{GHz}$, $4 \mathrm{~GB}$ RAM의 컴퓨터 환경에서 OpenCV와 $\mathrm{C}++$ 을 이용하여 구현하였다. 실험데이터로는 Fig. 28과 같이 CASIA Iris Image Database Version 4.0 홍채 데이터베이스를 이용하 였으며 기존의 속눈썹 제거 방법들과 제안하는 방법을 구현 하여 홍채정보 보존율을 비교하였다[10].
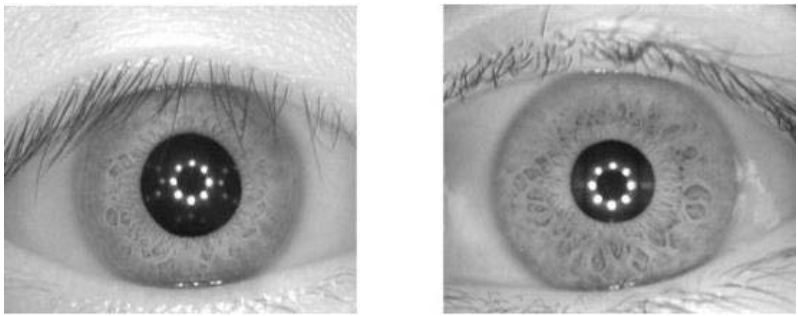

Fig. 28. CASIA iris image database version 4.0 samples

Zhaofeng $\mathrm{He}$ 의 방법은 홍채영역 내에서 속눈썹 포함 영 역 $\mathrm{EA}$ 와 속눈썹 미포함 영역 $\mathrm{IA}$ 를 임의로 지정하고 두 영 역에 대한 히스토그램을 분석하여 임계점을 설정하여 속눈 썹을 검출하는 방법으로 아래 Fig. 29와 같이 홍채특징까지 속눈썹으로 오검출되거나 일부 속눈썹은 $\mathrm{EA}$ 를 벗어나 검출 되지 않는 경우가 발생하였다.

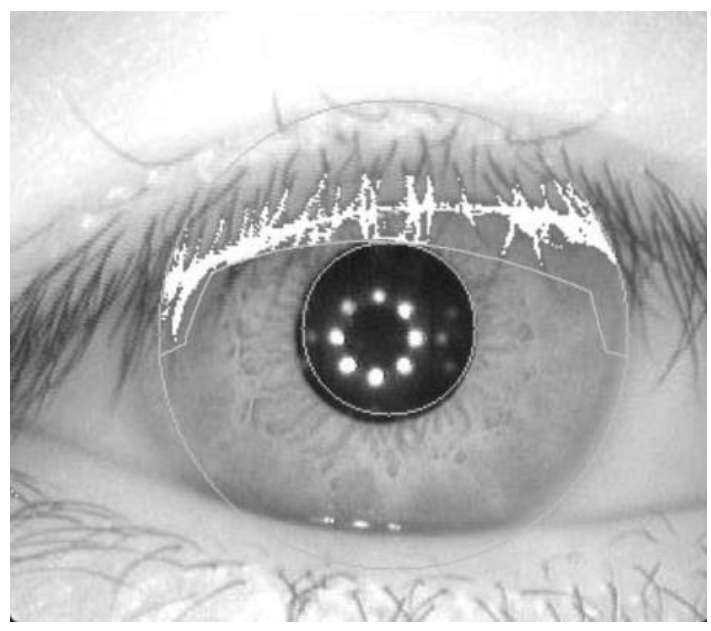

Fig. 29. Eyelashes detection by Zhaofeng He's method

또한 Ting Wang의 방법은 눈 전체 영상의 히스토그램에 대하여 Gaussian Mixture Model을 통해 여러 개의 가우시 안으로 나타내고 속눈썹을 포함하는 가우시안 영역을 통해 속눈썹을 검출한다. 이 방법은 눈 영상의 조명상태에 따라 영향을 많이 받아 Fig. 30과 같이 일부 속눈썹이 검출되지 않는 문제점이 있다. 


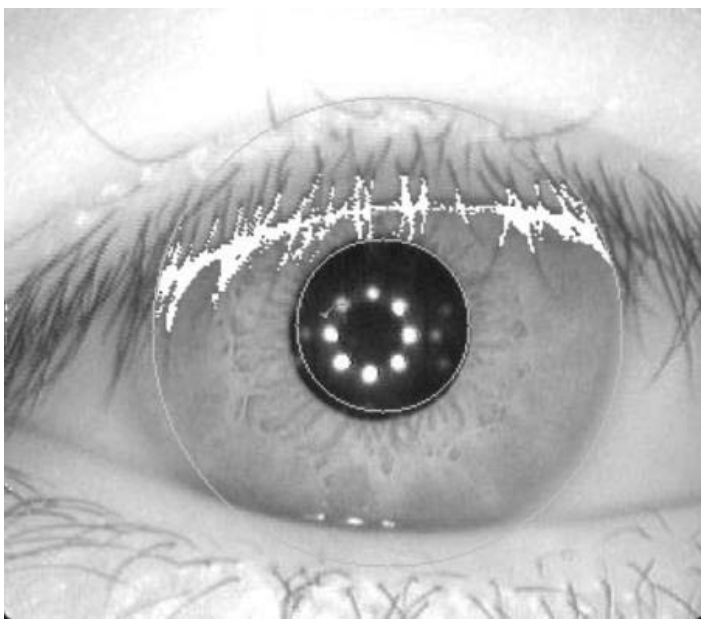

Fig. 30. Eyelashes detection by Ting Wang's method

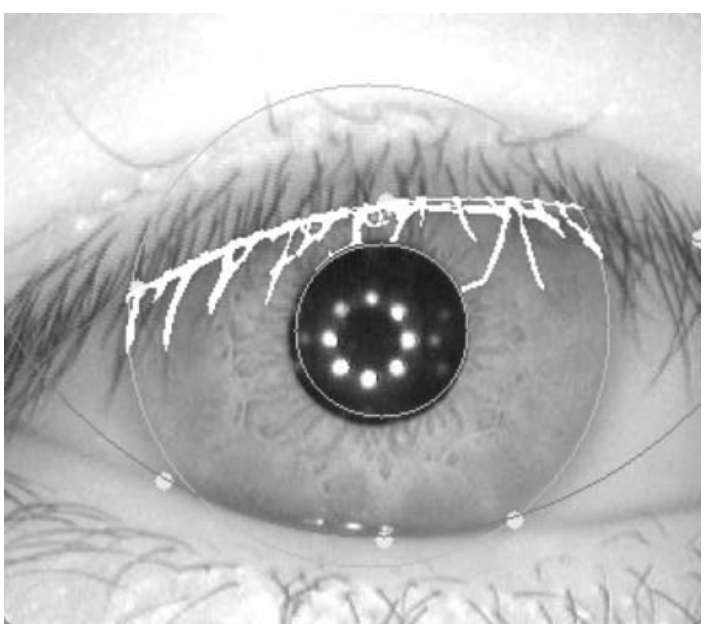

Fig. 31A. Result of eye image sample1

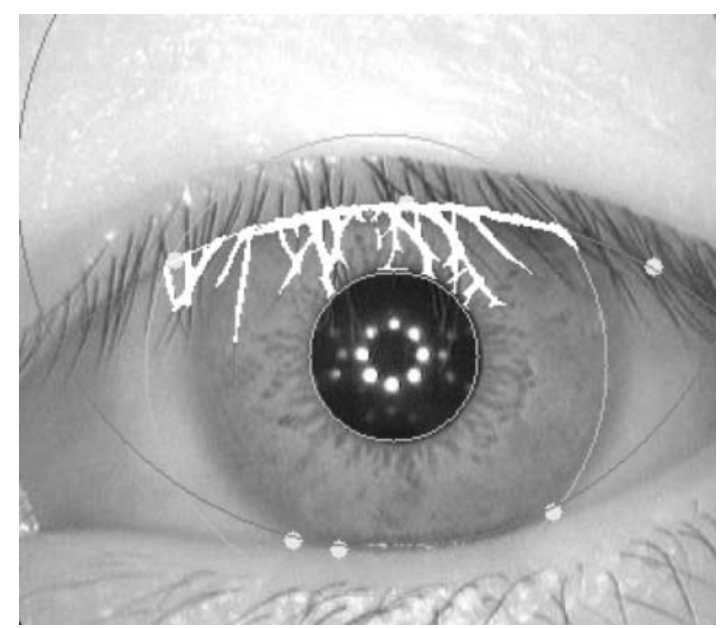

Fig. 31B. Result of eye image sample2

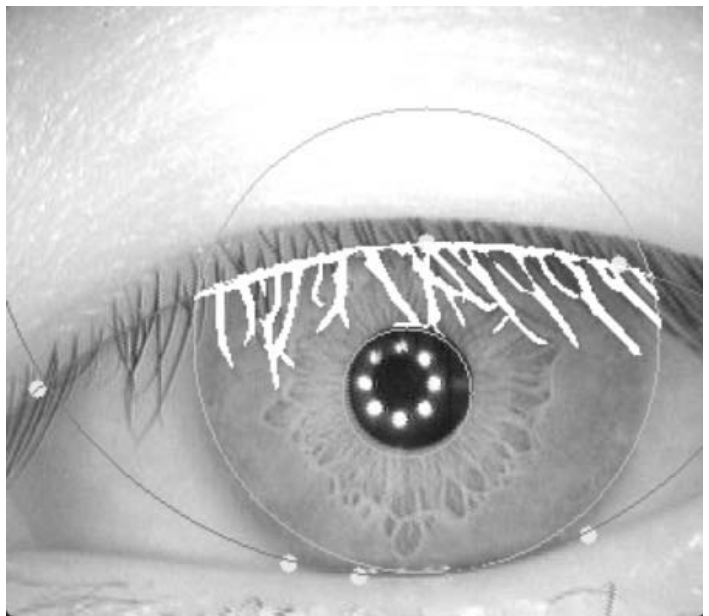

Fig. 31C. Result of eye image sample3

Fig. 31. Eyelashes detection by proposed method

따라서 기존의 방법들은 홍채코드 생성 시 고유한 홍채특 징의 일부가 손실되어 저장되므로, 이후 홍채인식에 활용될 경우 오인식률을 높이는 원인이 된다. 그러므로 이러한 문 제점을 해결하기 위해 Fig. 31과 같이 동공과 홍채 테두리 를 검출하고, Gabor Filter를 기반으로 하여 눈꺼풀 곡선과 속눈썹 후보를 검출하여 홍채영역 내에서 눈꺼풀 곡선과 교 차되거나 인접한 속눈썹 후보를 속눈썹으로 결정하는 방법 을 제안한다.

기존의 방법들과 제안하는 방법의 비교평가는 CASIA iris image database에서 속눈썹이 홍채영역에 포함된 샘플 영상 300 개를 이용하여 Table 1 과 같이 홍채영역에서의 속 눈썹 제거를 통한 홍채데이터의 보존율과 속눈썹 검출속도 를 비교하였다.

Table 1. Comparison of proposed method with the previous methods

\begin{tabular}{c|c|c|c}
\hline methods & $\begin{array}{c}\text { previous } \\
\text { method 1 } \\
\text { evaluation } \\
\text { items }\end{array}$ & $\begin{array}{c}\text { previous } \\
\text { method 2 } \\
\text { (Ting Wang) }\end{array}$ & $\begin{array}{c}\text { proposed } \\
\text { method }\end{array}$ \\
\hline $\begin{array}{c}\text { iris data } \\
\text { preservation rate }\end{array}$ & $89.7 \%$ & $91.4 \%$ & $93.1 \%$ \\
\hline process speed & $105 \mathrm{~ms}$ & $172 \mathrm{~ms}$ & $346 \mathrm{~ms}$ \\
\hline
\end{tabular}

제안하는 방법에서 속눈썹 끝부분의 두께가 얇아 Gabor Filter에 의한 컨벌루션 결과 값이 비교적 작게 나타나는 경 우가 발생하여 Fig. 32와 같이 일부 검출이 되지 않는 문제 점이 발생하였다. 이러한 문제점을 해결하기 위해서는 각도 값뿐만 아니라 주파수 또한 다양한 값을 사용하여 검출하는 것이 정확성을 향상시킬 수 있을 것으로 예상된다. 


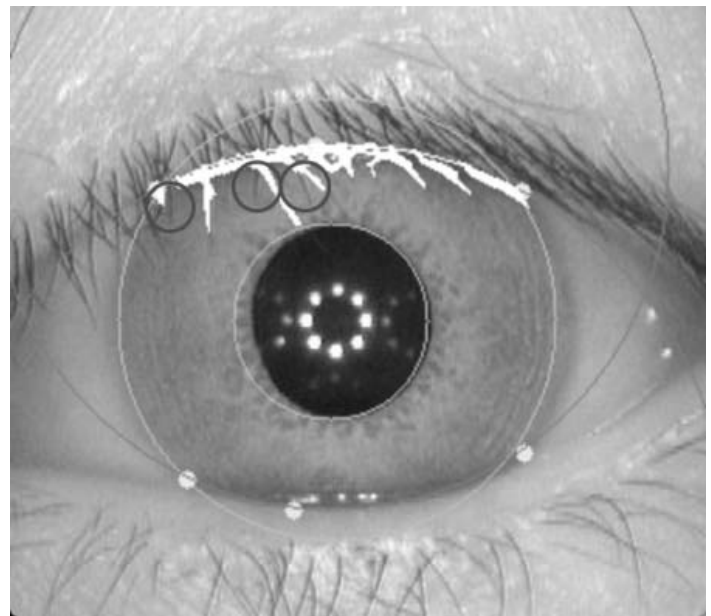

Fig. 32. Problem of proposed method

\section{5. 결 론}

본 논문에서는 홍채인식에서 정확도에 영향을 줄 수 있 는 속눈썹을 Gabor Filter를 이용하여 제거하는 방법을 제 안하였다. 기존 방법은 홍채영역에서 속눈썹 포함 영역(EA) 과 속눈썹 미포함 영역(IA)을 임의로 설정하고 히스토그램 분석을 통하여 속눈썹을 검출하는데, 이는 사람에 따라 다 른 속눈썹의 길이에 강인하게 검출할 수 없으며, 잘못된 임 계값이 설정될 경우 홍채특징까지 속눈썹으로 검출되는 단 점이 있다. 또한 Gaussian Mixture Model을 이용한 검출 방법은 눈 영상의 히스토그램 모양에 따라 속눈썹이 결정 되므로 속눈썹 일부가 검출되지 않는 문제점이 있다. 이러 한 문제점을 해결하기 위해 본 논문에서 제안한 방법은 속 눈썹이 눈꺼풀 곡선과 인접하거나 교차한다는 특징을 이용 하여 홍채영역에서 눈꺼풀 곡선을 검출하고, 다양한 각도 파라미터 값을 갖는 Gabor Filter를 통해 속눈썹 후보를 검 출하여 다양한 형태의 속눈썹을 검출할 수 있었으며, 이를 통해 홍채영역에 덮인 속눈썹을 정확히 제거함으로써 기존 방법보다 약 $4 \%$ 정도의 홍채데이터를 보존할 수 있었다. 향후 연구는 제안하는 방법을 기반으로 외부환경에 의한 홍채인식의 오인식률을 최소화하는 방법에 대하여 연구할 예 정이다.

\section{References}

[1] S. P. Pingat, S. Rakhecha, R. Agrawal, S. Mhetre, and P. Raushan, "Real Time Smart Car Security System by Using Biometrics", in International Journal of Innovative Technology and Exploring Engineering(IJITEE), Vol.2, pp.166-168, 2013.

[2] J. K. Schneider, "A Transformative Method for Conducting E-Commerce in The 21st Century", Biometrics, Smartphones and The E-Wallet, 2011.

[3] J. Daugman, "How Iris Recognition Works", in Circuits and Systems for Video Technology, IEEE Transaction, Vol.14, pp.21-30, 2004.

[4] S. Deepak, K. Ashok, "Iris Recognition - An Effective Human Identification", in International Journal of Computing and Business Research, Vol.2, pp.1-12, 2011.

[5] H. Zhaofeng, T. Tieniu, S. Zhenan, and Q. Xianchao, "Robust Eyelid, Eyelash and Shadow Localization for Iris Recognition”, IEEE International Conference, pp.265-268, 2008.

[6] W. Ting, "Improved and robust eyelash and eyelid location method", in Wireless Communications \& Signal Processing(WCSP), pp.1-4, 2012.

[7] J. R. Movellan, "Tutorial on Garbor Filters", GNU Free documentation, pp.1-20, 2002.

[8] J. Kamarainen, "Gabor Features in Image Analysis", in Image Processing Theory, Tools and Applications(IPTA), pp.13-14, 2012.

[9] K. Carolyn, B. Dana, and S. Jack, "Finding Circles by an Array of Accumulators", in Communication of the ACM, Vol.18, No.2, pp.120-122, 1975.

[10] CASIA Iris Image Database Version 4.0[Internet], http:// biometrics.idealtest.org/dbDetailForUser.do?id=4

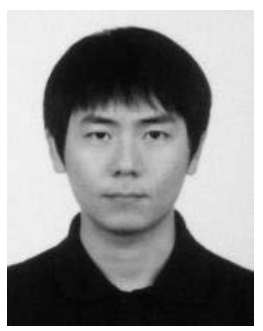

\section{김 성 훈}

e-mail : limiteddaily@gmail.com 2013년 가천대학교 컴퓨터미디어학과(학사) 2013년 현 재 가천대학교 전자계산학과 석사과정

관심분야: 영상처리, 컴퓨터비전 등 


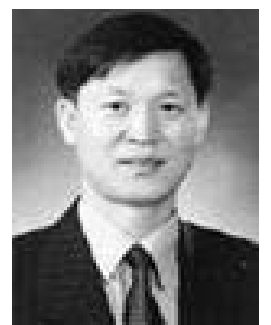

\section{한 기 태}

e-mail :gthan@gachon.ac.kr

1982년 충남대학교 계산통계학과(학사)

1990년 한양대학교 전자계산학과(공학석사)

2001년 한양대학교 전자계산학과(공학박사)

2009년 2010년 University of Texas at

Austin, Researching professor

2010년 현 재 가천대학교 컴퓨터공학과 교수

관심분야: 컴퓨터비전, 영상처리, 스마트객체 응용기술, 모바일

콘텐츠 등 